v.12, n.1

Vitória-ES, Jan.-Fev. 2015

p. $80-103$ ISSN 1808-2386 DOI: http://dx.doi.org/10.15728/bbr.2015.12.1.4

\title{
Jump Diffusion Modelling for the Brazilian Short-Term Interest Rate
}

\author{
José Carlos Nogueira Cavalcante Filho ${ }^{\dagger}$ \\ Cornell University \\ Edson Daniel Lopes Gonçalves ${ }^{\Omega}$ \\ $E B A P E / F G V$
}

\begin{abstract}
In order to capture the informational effect of the Brazilian short-term interest rate (SELIC rate) by Poisson jumps, we build on the tests conducted by Das (2002) and Johannes (2004), which show the significance of such structures for U.S. Federal Open Market Committee (FOMC) announcements. As in the above researches, we have found evidence that a relevant amount of the short-term volatility in the fixed income market is captured by introducing jumps on the stochastic process of the short-term rate. This structure also allows the verification of the information content of specific events, such as Brazilian monetary policy authority (COPOM) meetings and public bond auctions.
\end{abstract}

Keywords: Stochastic process. Broadcasts. Selic rate. Poisson jumps. Fixed income.

JEL classification codes: C13, C22, G14.

\section{INTRODUCTION}

Received on 06/27/2013; reviewed on 12/18/2013; accepted on 01/16/2014; published on 02/05/2015

* Corresponding author:

$\dagger$. Master by IAPUC da Pontifícia Universidade

$\Omega$ Doctor in Economy by EPGE/FGV

Católica do Rio de Janeiro (PUC-Rio)

Type of contract: Teaching Assistant in S.C.

Type of contract: Professor in EPGE/FGV, from

EBAPE/FGV and researcher in CERI/FGV

Address: Centro de Regulação e Infraestrutura - FGV,

Johnson Graduate School of Management at

Praia de Botafogo, Rio de Janeiro - RJ - Brazil

Address: 114 East Avenue - Ithaca/NY/USA

Email: edson.goncalves@fgv.br

Email: jn457@ cornell.edu

Telephone: (+1) 607-379-1609

Telephone: (21) 3799-6246

Editor's Note: This article was accepted by Emerson Mainardes 
he modelling and estimation of the informational effect in financial instruments are well-explored themes in the literature, due to both the interpretative role and the potential benefits in the pricing structures of those instruments. Several studies in the 1970s and 1980s (FRENCH; ROLL, 1986; MERTON, 1976; PEARCE; ROLEY, 1985; SCHWERT, 1981) have provided empirical evidence of the effect of informational economic news. Despite the significance of this effect, however, the aforementioned authors were not able to incorporate it into asset pricing structures. Another common feature in the aforementioned studies is the use of surveys as information sources for market expectations (PARKER, 2007). More recent studies, however, use the extraction of implicit expectations in financial instruments as an information source, which generates more realistic and tractable results.

Andersen et al. (2003), using high-frequency data of the US Dollar exchange rate against several foreign currencies (British Pound, Yen, Swiss Franc and Euro) to model economic news surprises, concluded that such surprises ${ }^{1}$ produce conditional jumps that characterize the average speed of the adjustment trajectory. Another interesting finding of the above study is that the market reacts asymmetrically; specifically, negative news has a greater impact than positive news.

Balduzzi et al. (2001) also indicated that macroeconomic announcements have significant impacts on financial instruments rates. Using intraday data from the U.S. bond market to investigate the informational effect of announcements, the authors concluded that 17 types of announcements impact bond prices. The effects of the announcements vary greatly depending on bond maturity but, in general, generate a substantial increase in price volatility ex-post the announcements.

Despite the huge amount of available information and the speed at which it propagates in markets, unanticipated informational shocks occur regularly. Such events tend to impact discount rates and therefore the prices and trading spreads of fixed income securities. Part of modern macroeconomic theory is based on the application of unexpected shocks as a monetary policy instrument to maximize their effect and minimize the policy conducting cost. Many of the existing term structure models imply that interest rates move continuously,

\footnotetext{
${ }^{1}$ Surprise is the difference between ex-ante and ex-post market expectations concerning an economic announcement.
} 
following diffusion processes. Recent studies show strong empirical evidence that rates contain unexpected and discontinuous changes of great magnitude.

A growing stream of literature explicitly incorporates jumps in modeling the rate dynamics. Johannes (2004) developed tests for jumps in rates and found strong evidence of their presence in three-month T-Bills. Farnsworth and Bass (2003) modeled the federal funds rate as a process with jumps and concluded that this structure explains most of the yield curve movements. Lund et al. (2004) also found strong evidence that jumps are important for ensuring the quality of the model fit, especially in the accommodation of outliers in the shortterm interest rate.

There is strong evidence for an intense and short-living interest rate volatility component in emerging markets. Through the experiments conducted by Edwards and Susmel (2003) it is clear that high volatility states in the short-term interest rate are relatively common, especially after 1994, for the selected sample of countries. As stated by the authors, there are three potential explanations for these occurrences in emerging markets: the "excessive" capital mobility, the floating exchange rate regimes, and contagion effects. Particularly in the Brazilian case, these states were found to last approximately one week, what advocates for the presence of typical jump behavior in the short-term interest rate.

The main objective of the present paper is to capture the informational effect of the Brazilian short-term interest rate (SELIC rate) using Poisson jumps. To this end, we build on the tests conducted by Johannes (2004) and Das (2002), which show the significance of Poisson jumps structure for U.S. Federal Open Market Committee announcements. As in the above-mentioned articles, we find evidence that much of the short-term volatility in fixed income markets is captured by introducing jumps in the stochastic process for the short-term interest rate. Additionally, our results indicate the superiority of the combination of OrnsteinUhlenbeck process with jumps and ARCH (1) variance with respect to the other models estimated. We present two applications of the jump-enhanced models in specific market events: the day-of-the-week effect (auctions of government bonds) and the meeting days of the Brazilian monetary policy authority (COPOM). In both cases, there is a greater likelihood of jumps in the SELIC rate around these respective dates.

\section{METHODS AND DATA}

Modeling interest rates with stochastic processes tends to be more complex than similar ventures on stocks or foreign exchange instruments. This increased complexity is a result of the mean reversion behavior found in interest rates, which is probably caused by agents' 
overreaction.

The mean reversion behavior also makes the likelihood function of the process dependent on the time of occurrence and reversion intensity. Another complicating factor is the existence of few closed solutions for stochastic differential equations of diffusions with jumps and mean reversion.

The basic stochastic process adopted in this work is a diffusion with mean reversion and jumps, following the functional form proposed by Das (2002):

$$
d r=k(\theta-r) d t+v d W+J d \pi(h)
$$

Where $\theta$ is the parameter of long-term trend for the rate $\mathrm{r}$, which reverts to its mean with rate $k$.

The interest rate therefore evolves according to a mean reverting Ornstein-Uhlenbeck process and a Poisson process that generates the random jump $I$. The coefficient of variance is $v^{2}$, and frequency of jumps is generated by the parameter $h$ (number of jumps per period). The intensity of jumps can be constant or generated from a probability distribution. The diffusion and Poisson process are independent of both each other and $I$.

The process described by equation (1), despite not being the only process estimated in this study, nests the others, once those are particular cases of the proposed structure. A simple diffusion, for example, occurs when the parameter $h$ is null. Other possibilities are models with the Gaussian component variance as $\mathrm{ARCH}(1)$, as described by the following equation: ${ }^{2}$

$$
v\left(t_{2}+\Delta t\right)^{2}=b_{0}+b_{1} \cdot\left\{r\left(t_{2}\right)-E\left[r\left(t_{2}\right) \mid r\left(t_{1}\right)\right]\right\}^{2}
$$

From this structure, we unfold two models: a simple diffusion described by the basic functional form proposed by Das (2002) and an ARCH (1) variance enhanced diffusion. In this sense, four basic models are objects of study and comparison, namely:

\footnotetext{
${ }^{2}$ Where $t_{2}>t_{1}$ and $\Delta t=t_{2}-t_{1}$.
} 
- Ornstein-Uhlenbeck process;

- Ornstein-Uhlenbeck process with $\mathrm{ARCH}(1)$ variance;

- Ornstein-Uhlenbeck process with jumps; and

- Ornstein-Uhlenbeck process with jumps and ARCH (1) variance.

The estimation of diffusions with jumps is complicated for several reasons. The first and most obvious of these is the existence of discrete samples of data, while the model is formulated in continuous time. This leads, in general, to the use of discrete approximations of stochastic processes, such as the Euler or Bernoulli approximation, as in Ball and Torous (1983) - such approximations result in poorly specified models.

Among the various methods for estimation of jump diffusions (e.g., the Generalized Method of Moments and methods based on Monte Carlo Markov Chains), we adopt Maximum Likelihood Estimation (MLE). The choice for MLE was based in the possibility of using the characteristic function instead of the distribution function, without loss of quality in the results. ${ }^{3}$ In the literature, there are several analytical solutions for the characteristic function of stochastic processes, compared to only a few solutions that result in expression of the density function.

\subsection{LIKELIHOOD FUNCTION}

In order to estimate the jump-enhanced Ornstein-Uhlenbeck process with a discrete observed sample, we use a discrete approximation. According to Chan (2005), there are two major alternatives to perform this estimation: Poisson-Gaussian and Gaussian-Gaussian mixed distributions.

The limitations arising from the Poisson distribution truncation, indicated by Vlaar and Palm (1993), justify choosing the Gaussian-Gaussian with Bernoulli approximation framework. This approach follows the structure originally proposed by Ball and Torous (1983), also used by Vlaar and Palm (1993) and Das (2002).

For the Bernoulli approximation, according to Ball and Torous (1983), it is assumed that at each instant of time a jump in interest rates either does or does not occur, which is reasonable at small time intervals. In one day, for example, one could expect no jumps or one at most.

This assumption regarding the Bernoulli approximation, which is detailed in Ball and Torous (1983) and Das (2002), leads to a likelihood function that can be written as follows:

\footnotetext{
${ }^{3}$ Guaranteed by the two-way relation between the distribution and characteristic functions.
} 


$$
L=\prod_{t=1}^{T} f[r(t+\Delta t) \mid r(t)]
$$

Once the likelihood function for the stochastic processes is defined, parameters' estimation can be obtained by maximizing it. Honore (1998) suggests that the likelihood function for jump-diffusions processes can have several singularities. ${ }^{4}$ This finding indicates the low reliability of estimates regarding jump-diffusions made using the maximum likelihood method. According to Honore (1998), several seminal studies, such as Jorion (1988) and Ball and Torous (1983), perform maximum likelihood estimation without concern for these problems.

To solve the singularities problem, Honore (1998) proposes a restriction on the optimization space: the variances of the Gaussian mixture should be assumed to be proportional to each other. If we have a mixture of $N_{1}\left(\mu_{1}, \sigma_{1}\right)$ and $N_{2}\left(\mu_{2}, \sigma_{2}\right)$ such as:

$$
L=w \cdot f_{N_{1}\left(\mu_{1}, \sigma_{1}\right)}+(1-w) \cdot f_{N_{2}\left(\mu_{2}, \sigma_{2}\right)}
$$

The solution proposed in Honore (1998) is to impose that $\sigma_{1}^{2}=\alpha \cdot \sigma_{2}^{2}$, with $\alpha$ being a non-zero finite constant. This restriction prevents the occurrence of singularities generated by $\sigma_{1}=0$ and $\sigma_{2} \neq 0$ (or vice versa). Moreover, when this condition is met, it is possible to obtain consistent and asymptotically normal estimates.

For our particular functional form of Gaussian mixture, $q$ being the weight parameter, the variances are $\sigma_{1}^{2}=v^{2} \Delta t+\gamma^{2}$ and $\sigma_{2}^{2}=v^{2} \Delta t$. Therefore, one of the variances can be written as a function of the other, or $\sigma_{1}^{2}=\left(1+\gamma^{2} / \sigma_{2}^{2}\right) \cdot \sigma_{2}^{2}$. To satisfy the solution proposed by Honore (1998), it is sufficient that $\left(1+\gamma^{2} / \sigma_{2}^{2}\right)$ is non-null (always satisfied since $\gamma^{2} \geq 0$ and $\sigma_{2}^{2} \geq 0$ ) and finite. ${ }^{5}$

\footnotetext{
${ }^{4}$ For example, when one of the variances in the Gaussian mixture tends to zero and the other does not.

${ }^{5}$ Satisfied tautologically by the likelihood function definitions.
} 
For the estimation, we employed the optimization algorithms of Berndt-Hall-HallHausman, Broyden-Fletcher-Goldfarb-Shanno and Simplex. For the procedure, we performed a two-step estimation: the first without restrictions on parameters, using the Simplex algorithm for calibration of the initial values of the second estimate; the second with appropriate restrictions in the optimization space, using as initial conditions the values found in the previous step.

A particularity of the optimization software used ${ }^{6}$ regarding the Simplex algorithm is that it was unable to determine the standard deviation of the estimates. The parameters' standard deviation was only obtained in the second stage of estimation.

In order to compare models, we used Akaike and Schwarz's information criteria. According to Ramezani and Zeng (2007), the main advantage in the use of information criteria versus likelihood tests is the possibility of simultaneous comparison of several models (versus pair comparison in likelihood tests).

\subsection{DATA}

The data set used in this work is the Brazilian short-term interest rate (SELIC rate), collected from the database of the Brazilian Central Bank (2010). The sample contains 2512 daily observations of the rate between 01/24/2000 and 01/22/2010.

During this period, the annualized SELIC rate ranged from $26.35 \%$ at the beginning of 2003 to $8.64 \%$ in late 2009. The trajectory is presented in Figure 1 below, highlighting the points of discontinuity ${ }^{7}$ of the rate.

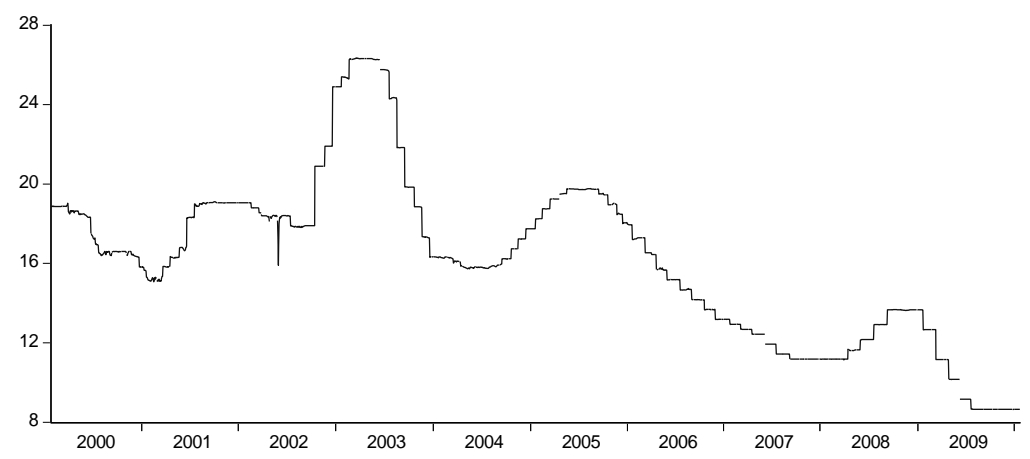

Figure 1 - Annualized SELIC Rate

The SELIC rate variation ${ }^{8}$ is presented below, in Figure 2.

\footnotetext{
${ }^{6}$ Estima RATS $^{\mathrm{TM}}$

${ }^{7}$ More prominently in 2003 and 2009, what might suggest jump occurrences.

${ }^{8}$ Here defined as the first difference of the variable $\left(\right.$ SELIC $\left._{\mathrm{t}+1}-\mathrm{SELIC}_{\mathrm{t}}\right)$.
} 


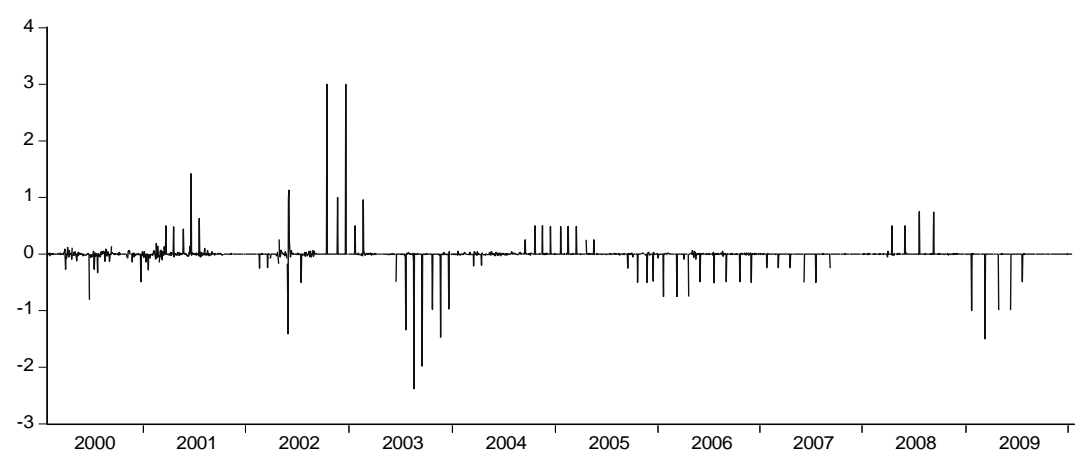

Figure 2 - SELIC rate variation

As shown in the figure above, 2002 and 2003 show greater oscillations than other years analyzed, likely as a result of the uncertainty about monetary policy that occurred during the election period.

The main descriptive statistics for the SELIC rate and its first difference are shown in Table 1.

Table 1 - SELIC and $1^{\text {st }}$ Difference Descriptive Statistics

\begin{tabular}{|c|r|r|}
\hline & SELIC & $\begin{array}{c}\text { SELIC 1 } \\
\text { difference }\end{array}$ \\
\hline Mean & 16.1963 & -0.0041 \\
\hline Median & 16.3400 & 0.0000 \\
\hline Maximum & 26.3500 & 3.0000 \\
\hline Minimum & 8.6400 & -2.3800 \\
\hline Std. Deviation & 4.1284 & 0.1542 \\
\hline Assimetry & 0.3087 & 2.4218 \\
\hline Kurtosis & 3.0409 & 172.3494 \\
\hline Observations & 2512 & 2511 \\
\hline
\end{tabular}

The excess of kurtosis in SELIC's first difference, according to Das (2002) suggests for the use of jump-enhanced models. Moreover, in Becker (1991), the failure of pure Gaussian models to explain the rate of short-term interest is evident.

The results for the Jarque-Bera test, whose null hypothesis is normality in the data are shown in Table 2 below. 
Table 2 - Jarque-Bera Normality Test

\begin{tabular}{|c|r|r|}
\hline & SELIC & $\begin{array}{c}\text { SELIC 1 } \\
\text { difference }\end{array}$ \\
\hline Test statistics & 40.0717 & 300301 \\
\hline P-value & 0.0000 & 0.0000 \\
\hline
\end{tabular}

It is clear that the high values of test statistics and the null p-value (at nine decimal places for the SELIC rate and its first difference) leads to the rejection of the null hypothesis for both the rate and its variation.

We also conducted the Augmented Dickey-Fuller test with intercept, whose null hypothesis is unit root. Analyzing the results, shown in Table 3 - Augmented Dickey-Fuller Test, we fail to reject the null hypothesis for the SELIC rate. On the other hand, we do reject the null hypothesis of unit root to the SELIC rate variation.

Table 3 - Augmented Dickey-Fuller Test

\begin{tabular}{|c|r|r|}
\hline & SELIC & $\begin{array}{c}\text { SELIC 1 } \\
\text { difference }\end{array}$ \\
\hline Test statistics & -0.6932 & -8.1549 \\
\hline P-value & 0.8465 & 0.0000 \\
\hline
\end{tabular}

\section{RESULTS}

First, we optimized the likelihood function for the Ornstein-Uhlenbeck process, with no constraints on the parameters. From the results, which are shown in Table 4 - Unrestricted Optimization Results, one can note some inconsistency, as the estimated value of the long-term mean for the rate $(\theta)$ is negative. This result seems to indicate that the SELIC rate tends toward a negative value in the long term, which does not make sense, as the SELIC rate is a nominal interest rate. Relevant constraints are, then, that the long-term mean of the process $(\theta)$ as well as the rate of reversion to this mean $(k)$ are non-negative. 
Table 4 - Unrestricted Optimization Results

\begin{tabular}{|c|c|c|c|c|}
\hline Estimate/Model & $O-U$ & $O-U A R C H(1)$ & $O-U w / j u m p s$ & $\begin{array}{l}O-U w / \text { jumps } \\
\text { and ARCH(1) }\end{array}$ \\
\hline$k$ & 0.029039 & -0.470999 & 0.008491 & -0.000001 \\
\hline$\theta$ & -0.191356 & 0.086037 & 0.065500 & 0.064645 \\
\hline$b_{0}$ & - & 0.000000 & - & 0.000000 \\
\hline$b_{1}$ & - & 25424.115759 & - & 75.238683 \\
\hline$q$ & - & - & 0.163000 & 0.192436 \\
\hline$\mu$ & & - & -0.000230 & 0.000804 \\
\hline$v^{2}$ & 0.000599 & - & 0.000001 & - \\
\hline$\gamma^{2}$ & - & - & 0.000015 & 0.000017 \\
\hline Log-Likelihood & 12690.69 & 13320.32 & 18969.51 & 31847.59 \\
\hline
\end{tabular}

From the identified ${ }^{9}$ constraints, we performed another round of optimization, the results of which can be seen in Table 5 below.

\footnotetext{
${ }^{9}$ The active optimization constraints were $\theta \geq 0$ and $k \geq 0$.
} 
Table 5 - Restricted Optimization Estimates (Std. Dev. In Parentheses)

\begin{tabular}{|c|c|c|c|c|}
\hline Estimate/Model & $O-U$ & $O-U A R C H(1)$ & $O-U w / j u m p s$ & $\begin{array}{l}O-U w / j u m p s \\
\text { and } A R C H(1)\end{array}$ \\
\hline$k$ & $\begin{array}{l}-0.000001 \\
(0.000000)\end{array}$ & $\begin{array}{r}0.000000 \\
(0.000000)\end{array}$ & $\begin{array}{r}0.008497 \\
(0.006464)\end{array}$ & $\begin{array}{r}0.005113 \\
(0.004815)\end{array}$ \\
\hline$\theta$ & $\begin{array}{r}0.167200 \\
(0.019300)\end{array}$ & $\begin{array}{r}0.056922 \\
(0.035567)\end{array}$ & $\begin{array}{r}0.065700 \\
(0.078200)\end{array}$ & $\begin{array}{r}0.019268 \\
(0.129831)\end{array}$ \\
\hline$b_{0}$ & - & $\begin{array}{r}0.000481 \\
(0.000014)\end{array}$ & - & $\begin{array}{r}0.000000 \\
(0.000000)\end{array}$ \\
\hline$b_{1}$ & - & $\begin{array}{r}856.299130 \\
(152.924483)\end{array}$ & - & $\begin{array}{l}210.722922 \\
(10.446016)\end{array}$ \\
\hline$q$ & - & - & $\begin{array}{r}0.163000 \\
(0.007452)\end{array}$ & $\begin{array}{r}0.074213 \\
(0.005882)\end{array}$ \\
\hline$\mu$ & - & - & $\begin{array}{l}-0.000230 \\
(0.000192)\end{array}$ & $\begin{array}{l}-0.000548 \\
(0.000427)\end{array}$ \\
\hline$v^{2}$ & $\begin{array}{r}0.000599 \\
(0.000017)\end{array}$ & - & $\begin{array}{r}0.000001 \\
(0.000000)\end{array}$ & - \\
\hline$\gamma^{2}$ & - & - & $\begin{array}{r}0.000015 \\
(0.000001)\end{array}$ & $\begin{array}{r}0.000030 \\
(0.000001)\end{array}$ \\
\hline Log-Likelihood & 12689.80 & 12767.85 & 18969.51 & 19299.52 \\
\hline $\mathrm{AIC}^{10}$ & -10.11 & -10.17 & -15.13 & -15.40 \\
\hline $\mathrm{BIC}^{11}$ & -10.10 & -10.17 & -15.11 & -15.38 \\
\hline
\end{tabular}

Similarly, the results of a first attempt to perform the unconstrained optimization for the Ornstein-Uhlenbeck process with ARCH (1) variance can be seen in Table . These results also show inconsistencies, with the parameter $k$ violating the non-negative restriction ${ }^{12}$ and $b_{1}$ reaching exorbitant figures. Performing the optimization with the constraints discussed earlier, we obtained the results shown in Table .

\footnotetext{
${ }^{10}$ Akaike Information Criterion.

${ }^{11}$ Bayesian Information Criterion.

${ }^{12}$ According to the Ornstein-Uhlenbeck process definition.
} 
The results for the estimation of the jump-enhanced Ornstein-Uhlenbeck process parameters, both with and without $\mathrm{ARCH}(1)$ volatility, are shown in Table 4(unconstrained) and Table (constrained).

As can be seen in the results tables, the adopted information criteria indicate the clear advantage of the jump-enhanced process, both pure and with stochastic volatility. Another important issue is that the introduction of jumps generates a decrease in the variance parameter $\left(v^{2}\right)$, indicating that jumps account for a great portion of the SELIC rate volatility.

In the jump-enhanced Ornstein-Uhlenbeck process, the parameter representing the probability of a jump $(q)$ was estimated at $16.3 \%$. This indicates that, on average, a jump occurs every six days (or slightly more than one jump per week). In our estimation of the jump-enhanced Ornstein-Uhlenbeck process with $\mathrm{ARCH}(1)$ volatility, the value of this parameter was reduced, indicating that part of the rate variance is absorbed by the stochastic volatility in detriment of jumps.

In Das (2002), for a sample of the fed funds rate between 1988 and 1997, the estimated result for the jump probability $(q)$ with a similar framework is higher $(21.6 \%)$ than the estimated in the present study, what is consistent with the monetary policy and inflation targeting system of the last decade in Brazil.

It is also interesting to note the result for the long-term trend parameter of the interest rate $(\theta)$. The parameter value was consistently lower in Das (2002) than in the Brazilian case.

This shows that despite having less abrupt movements in the short rate, the basic rate in Brazil, in accordance with the sovereign risk of emerging countries, tends to operate with higher values than in consolidated markets.

It is not news for financial markets agents, particularly those dealing with fixed income securities, that certain dates often have higher volatility. The end of a month, for instance, tends to concentrate a higher volume of transactions. This effect is usually related to banks' extra efforts to meet or exceed their goals. Release dates for economic activity indicators typically exhibit higher volatility for the reasons discussed in previous sections.

In the following section, we develop two extensions to the jump-enhanced OrnsteinUhlenbeck process - the day of week effect and the Monetary Policy Committee (COPOM) 
meetings effect - attempting to capture the informational effect in the SELIC rate, following the framework described in Das (2002), through changes in the jump probability.

\subsection{DAY OF THE WEEK EFFECT}

As in other markets such as stocks and options, fixed income markets, especially the government bonds market, tend to exhibit greater volatility on certain days of the week. The Brazilian National Treasury, for example, repurchases securities prior to their maturity on Wednesdays, increasing the amount of business and therefore the volatility seen on this day of the week. Furthermore, auctions of government-issued bonds usually occur on certain days of the week - LTN, LFT and NTN-F Thursdays and NTN-B on Tuesdays and Wednesdays. ${ }^{13}$

In order to verify whether the jump probability in the SELIC rate is dependent upon the day of the week, we used a similar framework to that found in Das (2002), with the likelihood of jumps parameter following the structure below:

$$
q=q_{0}+q_{1} \cdot d_{1}+q_{2} \cdot d_{2}+q_{3} \cdot d_{3}+q_{4} \cdot d_{4}
$$

Where $q_{0}$ represents the probability of a jump on Fridays and the variables $q_{1}, q_{2}, q_{3} \mathrm{e}$ $q_{4}$ represent the incremental probability of a jump on, respectively, Mondays, Tuesdays, Wednesdays and Thursdays (versus Fridays). The variables $d_{1}, d_{2}, d_{3}$ e $d_{4}$ are dummies that assume value 1 when the day is, respectively, Monday, Tuesday, Wednesday and Thursday.

The estimations were carried out by maximum likelihood, similar to those discussed in previous sections. The results for the jump-enhanced Ornstein-Uhlenbeck process are shown in Table 6 below.

\footnotetext{
${ }^{13}$ LTN and NTN-F are fixed cash-flow bonds, similar to T-Bills and T-Bonds, respectively; LFT is indexed to SELIC rate and NTN-B is a kind of inflation protected bond, similar to American Treasury TIPs
} 
Table6 - Day of the Week Effect Estimates (Std. Dev. in Parentheses)

\begin{tabular}{|c|c|c|}
\hline Estimate/Model & $O-U w / j u m p s$ & $\begin{array}{l}O-U w / j u m p s \\
\text { and } A R C H(1)\end{array}$ \\
\hline \multirow{2}{*}{$k$} & 0.008487 & 0.005181 \\
\hline & $(0.006302)$ & $(0.005081)$ \\
\hline \multirow{2}{*}{$\theta$} & 0.065200 & 0.017024 \\
\hline & $(0.075800)$ & $(0.135650)$ \\
\hline \multirow{2}{*}{$v^{2}$} & 0.000001 & \\
\hline & $(0.000000)$ & - \\
\hline \multirow{2}{*}{$b_{0}$} & - & 0.000000 \\
\hline & - & $(0.000000)$ \\
\hline \multirow{2}{*}{$b_{1}$} & - & 215.880175 \\
\hline & - & (13.722084) \\
\hline \multirow{2}{*}{$q_{0}$} & 0.147200 & 0.045201 \\
\hline & $(0.017500)$ & $(0.010961)$ \\
\hline \multirow{2}{*}{$q_{1}$} & -0.018600 & 0.001827 \\
\hline & $(0.023400)$ & $(0.014020)$ \\
\hline \multirow{2}{*}{$q_{2}$} & -0.016100 & -0.014200 \\
\hline & $(0.022900)$ & $(0.013791)$ \\
\hline \multirow{2}{*}{$q_{3}$} & 0.023100 & 0.036552 \\
\hline & $(0.024600)$ & $(0.017170)$ \\
\hline \multirow{2}{*}{$q_{4}$} & 0.086600 & 0.113573 \\
\hline & $(0.025700)$ & $(0.020120)$ \\
\hline \multirow{2}{*}{$\mu$} & -0.000232 & -0.000547 \\
\hline & $(0.000196)$ & $(0.000302)$ \\
\hline \multirow{2}{*}{$\gamma^{2}$} & 0.000015 & 0.000030 \\
\hline & $(0.000001)$ & $(0.000003)$ \\
\hline Log-Likelihood & 18960.01 & 19299.73 \\
\hline AIC & -15.14 & -15.42 \\
\hline BIC & -15.12 & -15.39 \\
\hline
\end{tabular}

Analyzing the results, it is evident that the days with increased probability of jumps are, Thursdays, Wednesdays and Fridays. As previously mentioned, auctions of three types of government bonds (particularly LFT treasury bills, whose profitability is tied directly to the SELIC rate) tend to be concentrated on Thursdays.

Other potential determinants of the highest probability of jump occurrence on Wednesdays and Thursdays are, respectively, the Monetary Policy Committee meetings (whose results are announced usually on Wednesdays) and the disclosure of the minutes of these meetings (which usually occurs on the Thursdays following the meeting). Such 
arguments strengthen the relationship between informational shocks and the jump occurrences in the SELIC rate.

Results of the estimation carried out for the jump-enhanced Ornstein-Uhlenbeck process with $\mathrm{ARCH}(1)$ variance, which followed similar procedures to those discussed above, are shown in Table, which makes even clearer the fact that the highest jump likelihood occurs on Thursdays.

\subsection{EFFECT OF MONETARY POLICY COMMITTEE (COPOM) MEETINGS}

As discussed above, Monetary Policy Committee (COPOM) meetings most likely are one of the factors causing the increased likelihood of jumps in the SELIC interest rate on Thursdays. The following functional form, similar to Das (2002) for the likelihood of jumps, attempts to capture this effect:

$$
q=q_{0}+q_{1} \cdot d_{\text {COPOM }}
$$

Where $q_{0}$ represents the status quo for the jump occurrence probability, $q_{1}$ represents the incremental probability of jump occurrence on COPOM meeting days, and $d_{\text {CopoM }}$ is a dummy variable that assumes value 1 for the COPOM meeting dates.

Similar to previous sections, the parameters estimation of the jump-enhanced OrnsteinUhlenbeck process was performed by maximum likelihood; results are presented in Table 7 below. 
Table 7 - Monetary Policy Committee Meetings Estimates (Std. Dev. in Parenthesis)

\begin{tabular}{|c|c|c|}
\hline Estimate/Model & $O-U w /$ jumps & $\begin{array}{l}O-U w / j u m p s \\
\text { and } A R C H(1)\end{array}$ \\
\hline \multirow{2}{*}{$k$} & 0.008517 & 0.000000 \\
\hline & $(0.006484)$ & $(0.000000)$ \\
\hline \multirow{2}{*}{$\theta$} & 0.066600 & 0.246281 \\
\hline & $(0.076600)$ & $(0.038743)$ \\
\hline \multirow{2}{*}{$v^{2}$} & 0.000001 & - \\
\hline & $(0.000000)$ & - \\
\hline \multirow{2}{*}{$b_{0}$} & - & 0.000000 \\
\hline & - & $(0.000000)$ \\
\hline \multirow{2}{*}{$b_{1}$} & - & 206.634967 \\
\hline & - & (14.337213) \\
\hline \multirow{2}{*}{$q_{0}$} & 0.158600 & 0.070817 \\
\hline & $(0.008121)$ & $(0.006014)$ \\
\hline \multirow{2}{*}{$q_{1}$} & 0.097700 & 0.096621 \\
\hline & $(0.046400)$ & $(0.045047)$ \\
\hline \multirow{2}{*}{$\mu$} & -0.000232 & -0.000550 \\
\hline & (0.000196) & $(0.000376)$ \\
\hline \multirow{2}{*}{$\gamma^{2}$} & 0.000015 & 0.000029 \\
\hline & & \\
\hline Log-Likelihood & 18968.48 & 19293.27 \\
\hline AIC & -15.13 & -15.40 \\
\hline BIC & -15.12 & -15.38 \\
\hline
\end{tabular}

These results show that, on a typical day, the probability of a jump in the SELIC rate is around $16 \%$. This value, however, increases by 9 percentage points if the date is a COPOM meeting day.

It can be argued, therefore, that on days of COPOM meetings there is a $60 \%$ higher probability of a jump occurrence in the SELIC rate than on days without COPOM meetings. These results prove to be quite similar to those found by Das (2002) and Johannes (2004), showing a strong relationship between the COPOM announcements and jumps in the short term interest rate. With similar modeling, Margueron (2006) demonstrated the relationship between COPOM meetings and changes in the volatility of the SELIC rate.

Similarly, by maximum likelihood, we obtained the parameter estimates for the jumpenhanced Ornstein-Uhlenbeck process with $\mathrm{ARCH}(1)$ variance, whose results are shown in Table.

Again the results show that the probability of a jump increases greatly on COPOM meeting dates. Moreover, given the partial capture of the volatility in the rate by the stochastic 
volatility structure, the probability of jumps on COPOM meeting days (16\%) is more than double the probability on other days (7\%). Thus, the results of studying the day of the week effect demonstrate that the COPOM meetings are a highly influential variable on the jump probability of the SELIC rate.

\section{CONCLUSION}

This paper investigated the effects of incorporating Poisson jumps in stochastic processes for modeling the short-term interest rate in Brazil. The relevance of introducing jumps in modeling the U.S. short-term interest rate has been discussed in the works of Johannes (2004) and Das (2002), but papers in this field regarding Brazil and other emerging countries are still scarce.

Additionally to the traditional Ornstein-Uhlenbeck process structure, we also estimated models enhanced with jumps and stochastic $\mathrm{ARCH}(1)$ volatility. The estimates of these models were performed using maximum likelihood, and the computer algorithms converged quickly to quite reasonable results. According to the Akaike and Schwarz information criteria, the Ornstein-Uhlenbeck process with jumps and $\mathrm{ARCH}(1)$ variance proved to be superior to other models estimated.

Next, we performed two specific applications of the jump-enhanced models by examining the day of the week effect and the effect of Brazilian monetary policy authority meetings. The estimates were made analogously to those in the first stage, with the hypothesis that these effects would increase the likelihood of jumps.

We obtained robust results, showing that there is higher jump likelihood on Wednesdays and Thursdays, likely due to the Brazilian Treasury interventions, such as public bond auctions, that systematically occur on those days. The meeting days of the Brazilian monetary authority were also shown to have higher jump likelihood, characterizing them as informationally relevant.

It is worth to mention that although the presence of jumps in "special" dates is a widely known phenomenon in the Brazilian financial market, there was little or none scientific evidence for this. Furthermore, market practitioners now can count with or build on our experiments as a solid alternative for simple diffusion models in simulating future trajectories of the interest-rate stochastic process.

As potential extensions for future research, we suggest the following: experimentation with other structures, not only Poisson-Gaussian; study of the relationship between the 
incorporation of jumps in the short-term rate and the greater maturity rate movements; and finally, analysis of the effects of incorporating jumps in pricing financial instruments, in line with the U.S. Financial Accounting Standards Board's suggestion of the realization of stress test scenarios using jumps in interest rates.

\section{REFERENCES}

ANDERSEN, T. G. et al. Micro effects of macro announcements: real-time price discovery in foreign exchange. American Economic Review, v. 93, n. 1, p. 38-62, 2003.

BALDUZZI, P.; ELTON, E. J.; GREEN, T. C. Economic news and bond prices: evidence from the U.S. treasury market. Journal of Financial and Quantitative Analysis, v. 36, n. 4, p. 523-543, 2001.

BALL, C. A.; TOROUS, W. N. A simplified jump process for common stock returns. Journal of Financial and Quantitative Analysis, v. 18, n. 1, p. 53-65, 1983.

BECKER, D. N. Statistical tests of the lognormal distribution as a basis for interest rate. transactions of society of actuaries, v. 43, 1991.

BCB. Brazilian Central Bank. Taxa selic retrieved. 2010. Disponível em: $\langle$ http://www.bcb.gov.br/?SELICDIA>.

Chan, K. F. Modelling conditional heteroscedasticity and jumps in Australian short-term interest rates. Accounting and Finance, v. 45, p. 537-551, 2005.

DAS, S. R. The surprise element: jumps in interest rates. Journal of Econometrics, v. 106, n. 1, p. 27-65, 2002.

EDWARDS, S.; SUSMEL, R. Interest rate volatility in emerging countries. Review of Economics and Statistics, 2003.

FARNSWORTH, H.; BASS, R. The term structure with semi-credible targeting. Journal of Finance, v. 58, n. 2, p. 839-866, 2003.

FRENCH, K.; ROLL, R. Stock return variances: The arrival of information and the reaction of traders. Journal of Financial Economics, v. 17, n. 1, p. 5-26, 1986.

HONORE, P. Pitfalls in estimating jump-diffusion models. SSRN eLibrary, 1998.

JOHANNES, M. The statistical and economic role of jumps in continuous-time interest rate models. Journal of Finance, v. 59, n. 1, p. 227-260, 2004.

JORION, P. On jump processes in the foreign exchange and stock markets. Review of Financial Studies, v. 1, n. 4, p. 427-445, 1988.

LUND, J.; ANDERSEN, T. G.; BENZONI, L. Stochastic volatility, mean drift, and jumps in the short rate diffusion: sources of steepness, level and curvature. Econometric Society, North American Winter Meetings, v. 432, 2004. 
MARGUERON, F. L. Previsão de volatividade para os vértices da estrutura a termo de taxa de juros em reais brasileira. EPGE/FGV. 2006. Disponível em:

$<$ http://hdl.handle.net/10438/340>.

MERTON, R. C. Option pricing when underlying stock returns are discontinuous. Journal of Financial Economics, v. 3, n. 1-2, p. 125-144, 1976.

PARKER, J. The Impact Of Economic News On Financial Markets. Munich Personal RePEc Archive, 2007.

PEARCE, D. K.; ROLEY, V. V. Stock prices and economic news. Journal of Business, v. 58, n. 1, p. 49-67, 1985.

RAMEZANI, C.; ZENG, Y. Maximum likelihood estimation of the double exponential jumpdiffusion process. Annals of Finance, v. 3, n. 4, p. 487-507, 2007.

Schwert, G. W. The Adjustment of Stock Prices to Information about Inflation. Journal of Finance, v. 36, n. 1, p. 15-29, 1981.

VLAAR, P.; PALM, F. The message in weekly exchange rates in the european monetary system: mean reversion, conditional heteroscedasticity, and jumps. Journal of Business and Economic Statistics, v. 11, n. 3, p. 351-360, 1993.

\section{APPENDIX}

\section{DEFINITIONS}

\section{ORNSTEIN-UHLENBECK PROCESS}

A process is called an Ornstein-Uhlenbeck if satisfies the following stochastic differential equation:

$$
d X=k(\theta-X) d t+v d W
$$

Where $W$ is a standard Brownian motion, $\theta$ is the long term trend $(\theta \geq 0), k$ is the reversion rate to this trend $(k \geq 0)$ and $v$ is the volatility.

\section{COMPUTATIONAL ALGORITHMS}

PARAMETERS ESTIMATION

calendar 20001252

allocate 2512

open data selic1.prn

data $($ org $=$ obs $) / \mathrm{rf}$

set $\mathrm{dr}=(\mathrm{rf}-\mathrm{rf}\{1\}) / 100$ 
set $r=\operatorname{rf}\{1\} / 100$

$* * * * * * * *$ ORNSTEIN-UHLENBECK $* * * * * * *$

nonlin(parmset=base) $\mathrm{k}$ theta $\mathrm{v} 2$

nonlin (parmset $=$ constraint) $\mathrm{k}>=0.0$ theta $>=0.0$

frml resid $=\mathrm{dr}-\mathrm{k} *($ theta-r $) / 252$

frml archvar $=v 2$

frml func $=(\exp (-(($ resid $) * * 2) / \$$

$(2 * \operatorname{archvar} / 252))) /(2 * \%$ pi*archvar/252)**0.5

frml $\log \mathrm{l}=\log ($ func $)$

compute $\mathrm{k}=0.88$, theta $=0.16, \mathrm{v} 2=0.002$

nlpar(subiterations=10000)

maximize $($ method $=$ bfgs, iterations $=1000$, parmset=base + constraint $) \log 13 *$

******* ORNSTEIN-UHLENBECK VOL ARCH(1) ******

nonlin(parmset=base) $\mathrm{k}$ theta $\mathrm{b} 0 \mathrm{~b} 1$

nonlin (parmset $=$ constraint $)$ theta $>=0.0 \mathrm{k}>=0.0$

frml resid $=\mathrm{dr}-\mathrm{k}^{*}($ theta-r $) / 252$

frml archvar $=\mathrm{b} 0+\mathrm{b} 1 * \operatorname{resid}(\mathrm{T}-1) * * 2$

frml func $=(\exp (-(($ resid $) * * 2) / \$$

$(2 * \operatorname{archvar} / 252))) /(2 * \%$ pi*archvar/252)**0.5

frml $\log 1=\log ($ func $)$

compute $\mathrm{k}=0.88$, theta $=0.2, \mathrm{~b} 0=0.002, \mathrm{~b} 1=222.88$

$\operatorname{nlpar}($ subiterations $=10000)$

maximize $($ method=bfgs, iterations $=1000$,parmset=base+constraint $) \operatorname{logl} 4 *$ ******* ORNSTEIN-UHLENBECK W JUMPS ******

nonlin(parmset=base) $\mathrm{k}$ theta $\mathrm{v} 2 \mathrm{q} 0 \mathrm{mu}$ gamma2 
nonlin(parmset $=$ constraint $)$ theta $>=0.0 \mathrm{k}>=0.0$

frml $\mathrm{q}=\mathrm{q} 0$

frml archvar $=\mathrm{v} 2$

frml resid $=\mathrm{dr}-\mathrm{k}^{*}($ theta-r $) / 252$

frml func $=\mathrm{q}^{*}(\exp (-(($ resid-mu $) * * 2) / \$$

$(2 *(\operatorname{archvar} / 252+$ gamma 2$)))) /(2 * \%$ pi*archvar/252+gamma2 $) * * 0.5+\$$

$(1-\mathrm{q}) *(\exp (-(($ resid $) * * 2) / \$$

$(2 * \operatorname{archvar} / 252))) /(2 * \%$ pi*archvar/252)**0.5

frml $\log 1=\log ($ func $)$

compute $\mathrm{k}=0.88$, theta $=0.16, \mathrm{mu}=0.0003$, gamma2 $=0.00003, \mathrm{q} 0=0.2185, \mathrm{v} 2=0.0004$

nlpar(subiterations=10000)

$\operatorname{maximize}($ method $=$ bfgs, iterations $=1000$, parmset $=$ base + constraint $) \operatorname{logl} 6 *$

***ORNSTEIN-UHLENBECK W JUMPS AND ARCH(1)**

nonlin(parmset=base) $\mathrm{k}$ theta b0 b1 q0 mu gamma2

nonlin(parmset $=$ constraint $)$ theta $>=0.0 \mathrm{k}>=0.0$

frml $\mathrm{q}=\mathrm{q} 0$

frml resid $=\mathrm{dr}-\mathrm{k}^{*}$ (theta-r) $/ 252$

frml archvar $=\mathrm{b} 0+\mathrm{b} 1 * \operatorname{resid}(\mathrm{T}-1) * * 2$

frml func $=\mathrm{q}^{*}(\exp (-(($ resid $-\mathrm{mu}) * * 2) / \$$

$(2 *(\operatorname{archvar} / 252+$ gamma 2$)))) /(2 * \%$ pi $* \operatorname{archvar} / 252+$ gamma 2$) * * 0.5+\$$

$(1-q) *(\exp (-(($ resid $) * * 2) / \quad \$$

$(2 * \operatorname{archvar} / 252))) /(2 * \%$ pi*archvar/252)**0.5

frml $\log 1=\log ($ func $)$

compute $\mathrm{k}=0.88$, theta $=0.16, \$$

$\mathrm{mu}=0.0016$, gamma2 $=0.00002, \mathrm{q} 0=0.1241, \mathrm{~b} 0=0.0002, \mathrm{~b} 1=127.04$

nlpar(subiterations $=10000)$ 
$\operatorname{maximize}(\operatorname{method}=\mathrm{bhhh}$, iterations $=1000$, parmset $=$ base + constraint $) \log 17 *$

\section{DAY OF THE WEEK ESTIMATION}

calendar 20001252

allocate 2512

open data selicdds.prn

data(org=obs) / rf seg ter qua qui

set $\mathrm{dr}=(\operatorname{rf}-\mathrm{rf}\{1\}) / 100$

set $r=\operatorname{rf}\{1\} / 100$

$* * * * * * *$ ORNSTEIN-UHLENBECK W JUMPS $* * * * * *$

nonlin(parmset=base) $\mathrm{k}$ theta $\mathrm{v} 2 \mathrm{q} 0 \mathrm{q} 1 \mathrm{q} 2 \mathrm{q} 3 \mathrm{q} 4$ mu gamma2

nonlin(parmset $=$ constraint $)$ theta $>=0.0 \mathrm{k}>=0.0$

frml q $=\mathrm{q} 0+\mathrm{q} 1 * \operatorname{seg}+\mathrm{q} 2 *$ ter+q $3 * \mathrm{qua}+\mathrm{q} 4 * \mathrm{qui}$

frml archvar $=$ v2

frml resid $=\mathrm{dr}-\mathrm{k}^{*}($ theta-r $) / 252$

frml func $=\mathrm{q}^{*}(\exp (-(($ resid$-\mathrm{mu}) * * 2) / \$$

$(2 *(\operatorname{archvar} / 252+$ gamma2 $)))) /(2 * \%$ pi $* \operatorname{archvar} / 252+$ gamma 2$) * * 0.5+\$$

$(1-\mathrm{q}) *(\exp (-(($ resid $) * * 2) / \$$

$(2 * \operatorname{archvar} / 252))) /(2 * \%$ pi*archvar/252)**0.5

frml $\log 1=\log ($ func $)$

compute $\mathrm{k}=0.88$, theta $=0.16, \mathrm{mu}=0.0003$, gamma $2=0.00003, \mathrm{q} 0=0.2, \mathrm{q} 1=0.0, \mathrm{q} 2=0.0, \mathrm{q} 3=0.0$, $\mathrm{q} 4=0.0, \mathrm{v} 2=0.0004$

nlpar(subiterations=10000)

maximize $($ method=bfgs, iterations $=1000$, parmset $=$ base + constraint $) \operatorname{logl} 10 *$

$* * *$ ORNSTEIN-UHLENBECK W JUMPS AND ARCH(1)***

nonlin(parmset=base) $\mathrm{k}$ theta b0 b1 q0 q1 q2 q3 q4 mu gamma2 
nonlin(parmset $=$ constraint $)$ theta $>=0.0 \mathrm{k}>=0.0$

frml $\mathrm{q}=\mathrm{q} 0+\mathrm{q} 1 * \operatorname{seg}+\mathrm{q} 2 *$ ter $+\mathrm{q} 3 * \mathrm{qua}+\mathrm{q} 4 * \mathrm{qui}$

frml resid $=\mathrm{dr}-\mathrm{k} *($ theta-r $) / 252$

frml archvar $=\mathrm{b} 0+\mathrm{b} 1 * \operatorname{resid}(\mathrm{T}-1) * * 2$

frml func $=\mathrm{q}^{*}(\exp (-(($ resid-mu $) * * 2) / \$$

$(2 *(\operatorname{archvar} / 252+$ gamma 2$)))) /(2 * \%$ pi*archvar/252+gamma2 $) * * 0.5+\$$

$(1-\mathrm{q}) *(\exp (-(($ resid $) * * 2) / \quad \$$

$(2 * \operatorname{archvar} / 252))) /(2 * \%$ pi*archvar/252)**0.5

frml $\log \mathrm{l}=\log ($ func $)$

compute $\mathrm{k}=0.88$, theta $=0.16, \$$

$\mathrm{mu}=0.0016$, gamma2 $=0.00002, \mathrm{q} 0=0.08, \mathrm{q} 1=-0.002, \mathrm{q} 2=0.03, \mathrm{q} 3=-0.03, \mathrm{q} 4=0.07$, $\mathrm{b} 0=0.0002, \mathrm{~b} 1=127.04$

nlpar(subiterations $=10000)$

maximize $($ method=bfgs, iterations=1000, parmset=base+constraint $) \log 11$ *

\section{COPOM MEETINGS EFFECT ESTIMATION}

calendar 20001252

allocate 2512

open data selicdcopom.prn

data(org=obs) / rf cop

set $\mathrm{dr}=(\operatorname{rf}-\mathrm{rf}\{1\}) / 100$

set $r=\operatorname{rf}\{1\} / 100$

******* ORNSTEIN-UHLENBECK W JUMPS $* * * * * * *$

nonlin(parmset=base) $\mathrm{k}$ theta $\mathrm{v} 2 \mathrm{q} 0 \mathrm{q} 1 \mathrm{mu}$ gamma2

nonlin (parmset $=$ constraint $)$ theta $>=0.0 \mathrm{k}>=0.0$

frml q $=\mathrm{q} 0+\mathrm{q} 1 * \operatorname{cop}$

frml archvar $=\mathrm{v} 2$

frml resid $=\mathrm{dr}-\mathrm{k}^{*}($ theta-r $) / 252$

frml func $=\mathrm{q}^{*}(\exp (-(($ resid $-\mathrm{mu}) * * 2) / \$$ 


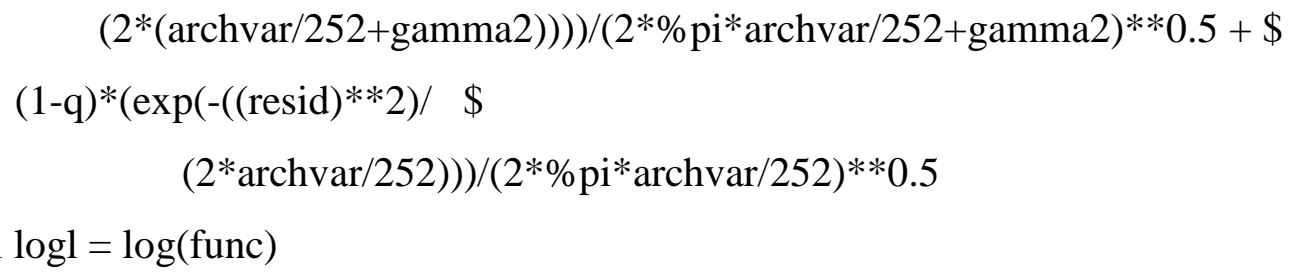

compute $\mathrm{k}=0.88$, theta $=0.005, \mathrm{mu}=0.00003$, gamma $2=0.0003, \mathrm{q} 0=0.1, \mathrm{q} 1=0.0, \mathrm{v} 2=0.00004$

nlpar(subiterations=10000)

$\operatorname{maximize}($ method=bfgs,iterations $=1000$,parmset=base+constraint $) \log 17$ ***ORNSTEIN-UHLENBECK W JUMPS AND ARCH(1)***

nonlin(parmset=base) $\mathrm{k}$ theta b0 b1 q0 q1 mu gamma2

nonlin (parmset $=$ constraint $)$ theta $>=0.0 \mathrm{k}>=0.0$

frml q $=\mathrm{q} 0+\mathrm{q} 1 * \operatorname{cop}$

frml resid $=\mathrm{dr}-\mathrm{k}^{*}($ theta-r $) / 252$

frml $\operatorname{archvar}=\mathrm{b} 0+\mathrm{b} 1 * \operatorname{resid}(\mathrm{T}-1) * * 2$

frml func $=\mathrm{q}^{*}\left(\exp \left(-\left((\text { resid-mu })^{* * 2}\right) / \$\right.\right.$

$(2 *(\operatorname{archvar} / 252+$ gamma 2$)))) /(2 * \%$ pi $* \operatorname{archvar} / 252+$ gamma 2$) * 0.5+\$$

$$
\begin{aligned}
& (1-\mathrm{q}) *(\exp (-((\text { resid }) * * 2) / \$ \\
& (2 * \operatorname{archvar} / 252))) /(2 * \% \text { pi } * \operatorname{archvar} / 252) * * 0.5
\end{aligned}
$$

frml $\log l=\log ($ func $)$

compute $\mathrm{k}=0.0005$, theta $=0.1, \$$

$\mathrm{mu}=0.0001$, gamma2 $=0.00001, \mathrm{q} 0=0.05, \mathrm{q} 1=0.05, \mathrm{~b} 0=0.00002, \mathrm{~b} 1=100.7$

nlpar(subiterations $=10000)$

$\operatorname{maximize}($ method=bfgs,iterations $=1000$,parmset=base + constraint $) \log 18 *$ 